\title{
Health Promoting Hospital: A Strategy for Reorientation toward Health Promotion
}

\author{
Mohsen Saberi Isfeedvajani, ${ }^{1}$ * \\ ${ }^{1}$ Medicine, Quran and Hadith Research Center \& Department of Community Medicine, Faculty of Medicine, Baqiyatallah University of \\ Medical Sciences, Tehran, Iran
}

*Corresponding Author: Mohsen Saberi Isfeedvajani, Medicine, Quran and Hadith Research Center \& Department of Community Medicine, Faculty of Medicine, Baqiyatallah University of Medical Sciences, Tehran, Iran. Tel: +98-21-81263619, Fax: +98-21-88068923 Email: drsaberihaji@gmail.com

Received: 6 Oct. 2015; Accepted: 29 Oct. 2015; Online Published: 11 Jan. 2016

Health promotion (HP) as already defined by the Ottawa Charter for Health Promotion is "the process of enabling people to increase control over and improve their health." The Network of Health Promoting Hospitals (HPH), established in 1990 by the World Health Organization (WHO), is the best-known example of health promotion reorientation in hospitals. It supports the implementation of health promotion and facilitates organizational change [1]. Since its establishment, the network has spread worldwide. Baqiyatallah Hospital has been a member of this network since 2015.

Organizational capacities are listed for health promotion implementation. Based on PRICES-HPH, a cross-sectional evaluation study of the International Network of Health Promoting Hospitals \& Health Services (HPH-Network), some organizational structures were defined as [1] a health promotion specific quality assessment routine; [2] an official hospital health promotion team; [3] a fulltime hospital health promotion coordinator; and [4] officially documented health promotion policies, strategies, or standards [2]. Additionally, 'regular health promotion projects and organization-wide programs', 'established health promotion management systems', and the 'integration of health promotion in existing quality management systems' were shown as other implementation capacities [3]. Based on a Taiwanese case study, these items were reported as organizational capacities: "more support from leadership", "a fine-tuned HP mission and strategy", "cultivated pro-HP habits of physical activities", "a supportive intramural structure", "an HP-inclusive system", and "improved management practices and enhanced staff participation" [4]. Another study showed that the five most reported facilitators are, (a) support from hospital superintendents, (b) support from unit/department directors, (c) HP-inclusive hospital development mission and goals, (d) funding from the government, (e) founding of HP-related committees, and (f) resources and healthy policies [5].

Although the reorientation of hospitals toward health promotion is widely recognized as a core strategy for developing quality within service provision, it involves a complex process, and an entire organization needs to be adjusted toward health promotion. Evidence shows that a systematic reorientation of hospitals often remains very limited, and hospitals' reorientation toward health promotion is still more a desirable goal than an organizational reality [1]. In a Taiwanese case study, these features were reported as barriers to HP implementation: "insufficient support from external environments", "leadership with limited autonomy and authority", "a preference for ideals over professionalism", "insufficient participation by physicians", "a lack of manpower and time", "a merit system with limited stimulating effect", "ineffective management practices in weak central project management", “a lack of integration", "insufficient communication and an inability to inculcate the staff on the importance of HP", and "inadequate staff participation" [4].

Organizational capacity building is an important issue in overcoming barriers to HP implementation which has been mentioned by several studies [1-5]. Organizational change toward HP implementation and the engagement of professionals with program implementation is based on three issues: the status, practices, and role-definition of professionals. For each issue, strategies have been proposed to facilitate health promotion reorientation, such as prioritization and status incentives for the status of professionals, transformational leadership for the practices of professionals, and training for the role-definition of professionals [1].

Other important issues were also reported. The first issue is that the HPH project can be sustained only when supported by both leadership and a devoted ground force which provide vision and aspiration, and ways and means to ensure a successful HPH implementation. Secondly, the integration of hospital accreditation and $\mathrm{HPH}$ is another initiative, and resistance is effectively reduced if the existing hospital accreditation scheme encompasses components of HP [4]. Fortunately HP components have 
been included in Iran's national hospital accreditation. Thirdly, it has been suggested that hospital leaders encourage staff to participate in international $\mathrm{HPH}$ conferences to recognize how the staff feels and to motivate them. Finally, it has been proposed that a hospital with good credentials of quality management, such as Baqiyatallah Hospital, should adopt the integration model and import HP components into the original quality management framework. The alternative option is the addition model. This model may be more appropriate for a beginner, as the particular HPH structure is relatively concrete, allowing relevant resources to be somewhat easily organized and HP issues and actions to be more visible [4].

\section{Acknowledgments}

The author would like to thank from the "Clinical Research Development Unit" of Baqiyatallah Hospital for their kindly cooperation.

\section{Authors' Contributions}

The author was involved in every stage of this study.

\section{Conflict of Interest}

The author declared no conflict of interest.

\section{References}

1. Wieczorek CC, Marent B, Osrecki F, Dorner TE, Dür W. Hospitals as professional organizations: challenges for reorientation towards health promotion. Health Sociol Rev. 2015(ahead-of-print):1-14.

2. Röthlin F, Schmied H, Dietscher C. Organizational capacities for health promotion implementation: results from an international hospital study. Health Promot Int. 2015;30(2):369-79. [DOI]

3. Röthlin F, Schmied H, Dietscher C. Health promotion implementation capacities in hospitals matter: results from the PRICES-HPH study. Health Promot Int. 2015:dav100.

4. Lee CB, Chen MS, Chien S-H, Pelikan JM, Wang YW, Chu CM-Y. Strengthening health promotion in hospitals with capacity building: a Taiwanese case study. Health Promot Int. 2014:dat089.

5. Lee CB, Chen MS, Wang YW. Barriers to and facilitators of the implementation of health promoting hospitals in Taiwan: a topdown movement in need of ground support. Int $\mathbf{J}$ Health Plann Manage. 2014;29(2):197-213. [DOI] 